Sanjin Sorel

Data przesłania tekstu do redakcji: 31.12 .2012 Data przyjęcia tekstu do druku: 21.08.2013

sanjin.sorel@xnet.hr

\title{
Druže Tito svi smo mi - ti
}

\begin{abstract}
Sorel Sanjin, Druže Tito svi smo mi - ti (Comrade Tito, All of Us Are - You). „Poznańskie Studia Slawistyczne” 5. Poznań 2013. Adam Mickiewicz University Press, pp. 203-212. ISBN 978-83-232-2636-9. ISSN 2084-3011.

The article describes different ways of depicting Josip Broz Tito in poems which embody socialistic values. The notion of the Government relies on the idea of the abscence, and the exact abscence requires the image in order to be effective. This is the key role of poetry, which conveyed the constructs of both individual and social illusion.
\end{abstract}

Keywords: Tito; poetry; image; illusion

U elementarnim crtama Titove su zasluge velike - organiziranje uspješnog antifašističkog otpora, oslobođenje zemlje te povratak nekih dijelova Hrvatske, glavna su uporišta u povijesnoj zbilji ex Jugoslavije. Kultivizacija Tita obrise zadobiva već tijekom drugog svjetskog rata, no kako me ne zanimaju uže povjesničarski elementi tog procesa već jedino slika koja se o njemu stvarala putem pjesništva ${ }^{1}$ unaprijed se ograđujem od gubitka širega konteksta. Važan mi se čini zaključak vezan uz društveno pamćenje, točnije uz njegov zaborav, kako iznosi Paul Connerton: totalitarizmima je zajednička praksa oduzimanja pamćenja vlastitim podanicima (Connerton 2004: 23). Pa ipak, proces proizvodnje „Idealnog vođe” putem pjesme započet je iz dvaju izvora - prvi je usmena lirika, drugi pak umjetnička. Stoga me interesiraju načini na kojima je književnost, odnosno pjesništvo stvaralo od Josipa Broza Tita arhetipsku, mitsku, božansku i očinsku figuru. Psihoanaliza svakako pruža puno interpretativnih mogućnosti vezanih uz ime Oca i Zakona, ali izbjegavat ću navedeni pristup što je više moguće, jer je o tome već sve više-manje rečeno.

\footnotetext{
${ }^{1} \mathrm{~A}$ i zbog ograničenosti prostora članka.
} 
Mašta, po Aristotelu, posreduje između percepcije i misli. Procesi u kojima mentalne slike koje dolaze iz osjetilnog dojma te se potom fiksiraju bitni su za manipulativne strategije svake ideologije. Ljubav prema njima, kao i svaka ljubav, emotivne je prirode, u politici ona pokušava „doći do srca i duše naroda”. Od spontanih, usmenih pjesama utemeljenih na stvarnim vrijednostima požrtvovnosti, junaštva, pravde pa do, rukovođenih od strane Partije, emocija prema istima, zapravo je put njihova stvaranja i nestajanja, sve do trenutka kada su postale samo petrificirane metafore. Stoga sedamdesetih godina 20. stoljeća, a posebno nakon Titove smrti, primjerice u pjesmi Ljerke Car Matutinović Kad te zaboli duša nema više ničega do li manire ${ }^{2}$. Da bi mašta bila djelotvorna slike koje ju hrane moraju imati snagu uvjerljivosti, ili drugim riječima moraju biti performativne. S vremenom, ekonomskim i političkim krizama, osobito nakon smrti društvo nije uspjevalo pronaći adekvatne strategije memorije, osobito kada komunikativno pamćenje koje se odnosi na blisku prošlost nestaje. Po Janu Assmanu kulturno pamćenje se ,zgrušava u simboličke figure za koje prianja sjećanje" (Assmann 2005: 61). Važno je od prisjećanja na povijest učiniti mit o njoj. Pripovijedanje i mit tako se ponovno pomiruju u ideologiji. Stoga, o kojem je to sjećanju riječ?

Dunja Rihtman-Auguštin je u priređenim partizanskim pjesmama o Titu (Rihtman-Auguštin, Bezić 1977), poznatim kao Partizanske iz Like koje je zabilježio kompozitor Miroslav Špiler 1944. g. ustvrdila kako folklor $^{3}$ ima i umjetničku i komunikacijsku funkciju. O potonjima je pisala u tekstu Folklor kao komunikacija u NOB-u (Rihtman-Auguštin 1975: 151-165). S obzirom da, zaključuje, klasični mediji nisu mogli do te mjere homogenizirati borce (radio i novine), budući da su bili uglavnom nedostupni, pjesma se nametnula sama po sebi, ona je bila "sastavni dio borbe” - veli Dunja Rihtman-Auguštin - svima razumljiva „šifra”. I s obzirom na pučki status tih pjesama i s obzirom na bliskost emocija i sadržaja koji su se njima prenosili. ,Šifra” je zapravo bila poznati kontekst od kojega su te pjesme neodvojive. U naglašeno ruralnoj, tradicionalnoj zemlji gotovo sve kulturne i vrijednosne topose određivala je vjera, religija, katolička crkva.

2 „Tito nije umro / I kada u daljini sijeva / ti znaš: On će umiriti grom” (Pešić 1981).

${ }^{3}$ Pod pojmom folklora podrazumijevam stav Vladimira Jakovljeviča Proppa koji u folkloru čini distinkciju između njegove materijalne i duhovne osnove, specificirajući ga u semantiku potonjega, još uže i književnoga stvaralaštva (Propp 1982). 
Stoga je posve shvatljivo da kulturno pamćenje ima i svoju sakralnu dimenziju, kako napominje to Jan Assmann: „Figure sjećanja imaju religiozni smisao i njihovo uprisutnjenje putem sjećanja često ima karakter svetkovine" ${ }^{4}$ (Assmann 2005: 62). Zapravo, socijalizam je vrlo blizu teologiji koja, po Karlu Löwithu, govori kako ljudi ne mogu egzistirati u historijskoj prošlosti, kao ni u sadašnjosti, nego jedino u budućnosti (Löwith 1990: 46). Povijest nade eshatološka je povijest, kao i socijalizma. Usto, što su utopijske. Ukoliko je Bog prvi promatrač koji izmiče promatranju (Biti 2000: 171), utoliko u njegovim socijalističkim manifestacijama on je morao i bio je, među ostalim i zbog izrazito tradicionalnog stanovništva, zamijenjen Realnim. Ukoliko ustrajavanje u vrlini, usprkos kušnjama, svjedoči snagu vjere, utoliko i ustrajavanje u borbi, revoluciji, usprkos nesrazmjeru protivnika, također svjedoči tu istu snagu. Bog i Revolucija su transcendentalni okviri, jednakosnažna utopija, eshatološka dakako. Mihovil Kombol je ustvrdio da crkvena prikazanja (Muka Svete Margarite) karakterizira vjerska krepost i snaga, a tu usporedbu Divna Zečević vodi prema Revoluciji - „Primarna je odanost revoluciji, a revolucija je ljubav i isključuje svaku drugu ljubav" (Zečević 1975: 190). U svojoj doktorskoj disertaciji Javob Taubes povlači paralelu između revolucije i eshatologije: „No znači li revolucija suprotstavljanje nekog novog totaliteta totalitetu svijeta, koji ga jednako obuhvatno, naime u temeljima, nanovo zasniva kao što ga niječe, tad je apokaliptika bitno revolucionarna" (Taubes 2009: 18). Štoviše, pjesme i o vjeri i o revoluciji osiguravaju zajedništvo, na što upućuje i Ivan Slamnig kada tvrdi kako pjesma ima najveću kohezijsku moć u društvenoj svijesti (Slamnig 1965: 14). Pjesme o Titu, njihovu kohezijsku moć, koje su mu osiguravale mitsko-sakralni status, realizirale su se putem rituala koji je osiguravao koherenciju, strukturu u vremenu kada je nije bilo. Bez obzira da li je riječ o individualnim ili sociokulturnim ritualima oni u oba slučaja metaforički određuju stvarnost tako što u nju unose red, u po/ratnim pak okolnostima oni imaju i političko-propagandni karakter. Pjesme o Titu služile su stvaranju kulturnih obrazaca - „kultura je izrasla iz rituala i rituali je održavaju djelotvornom; kroz rituale se kultura potvrđuje i opravdava sustav vrijednosti koji je karakterizira" (Biti, Marot-

\footnotetext{
${ }^{4}$ Paradigmatski su primjeri „religioznih” svetkovina sletovi za Dan mladosti koji su se održavali 25. svibnja, na Titov rođendan.
} 
-Kiš 2008: 212). Usmenim stvaranjem, pisanjem i komponiranjem navedenih pjesama opravdavala se i potvrđivala uzajamnost odnosa između stvarnosti i želje. Isto tako sakralni genotip prikriven svjetovnim oblicima sadržaja pjesme obuhvaćao je iste mehanizme koje sadržava pokrštavanje preko slavenskoga se sistema vjerovanja upisivala kršćanska ikonografija, što je etnografija navelike dokumentirala, primjerice u običajima Božića uklopljeni su već „postojeći ciklusi starijih obreda” (Čulinović-Konstatinović 1989: 122).

Nisu samo pjesme o Titu pridonosile njegovom božanskom statusu. Budući da je mit zapovjedan (Bart 1979: 244) - a Titov položaj metonimijski, dio koji predstavlja cjelinu - tada priče o njemu imaju intencionalnu moć. Kada je Vladimir Popović pisao poemu Oči, Ivan Goran Kovačić Jamu, Augustin Stipčević Sunce u ćeliji, Živko Jeličić poemu o partizanima Koliba u inju i, naravno, Jure Kaštelan petodijelnu poemu Tifusari, Glad, Žeđ, Vatra i Ognjica onda su oni kroz kontekst narodnooslobodilačke borbe, njezinu cjelinu, posredno govorili o najvažnijem njezinom dijelu - ,ruci” i ,srcu” Josipa Broz Tita. Bart kaže da ,smrt pretvara djelo u mit" (Bart 1979) što drugim riječima znači da su povijesne, tragične okolnosti pridonosile poistovjećivanju borbe s vođom, a sloboda izborena pod strašnim okolnostima ipak je sloboda. Za mit utoliko i bolje, budući da se time dokazuje junaštvo, što je svakako jednim dijelom dio usmene, epske tradicije koja preferira te muške osobine. Mažuranićeva Smrt Smail age Čengića najbolje opisuje na balkanskim prostorima cijenjene vrline. Ili kako bi Claude Lévi-Strauss rekao ,mitska misao, iako ne može da se oslobodi slika, može već da uopštava, dakle da ima naučni karakter; i ona se služi analogijama i poređenjima, čak i ako se (...) njene tvorevine uvek svode na novi raspored delova čija priroda ostaje nepromenjena" (Lévi-Strauss 1978: 61). Usto valja pripomenuti kako je jedan od krucijalnih toposa na kojima se formira mit - žrtvovanje (Kolsto 2005). Pjesma to nedvojbeno potvrđuje - „Imala sam jedinoga brata, / Dala sam ga Titi za soldata" (Rihtman-Auguštin, Bezić 1977). Glavna karakteristika obreda, osobito žrtvenog, je „da uspostavi zajedništvo kako među članovima zajednice, tako i među zajednicom i silama u koje ona veruje" (Janićijević 1986: 297). Budući da i pjesma ima istu, kohezijsku funkciju u zajednici prirodno je bilo da prisila žrtvovanja te tugovanje funkcioniraju paralelno. 
Za Spinozu je Supstancija Deus sive natura (Bog ili priroda) svako je biće njezin atribut (Cipra 2003: 47). Umjesto hijerarhije bića - njihov paralelizam. Bog ili priroda tako ne stvaraju poretke nego iz sebe izlučuju beskonačne atribute. Kao mitska figura Josip Broz Tito zauzima poziciju Boga, pak kao pojedinačno, ideološko biće - ,esencijalan privid” prirode „spoznajnog subjekta”. Jer ako su Bog ili priroda uzroci sebi, casua sui, onda se njihova beskonačnost emanira i na pojedinačne atribute, pojedince, svakog člana tog velikog organizma pojedinačno. Budući da je subjektima socijalističkog društva tako osigurana beskonačnost, a iz njih i beskonačna prava, nije niti čudno da je privid, zapleten u svoja proturječja bio relativno stabilan. Stoga je privid Tita važniji od Tita samog, jer on je alfa i omega ili kako bi Slavoj Žižek rekao - veliki Drugi ,otvara novi pristup statusu obmane u ideologiji: oni koje treba obmanuti ideološkom iluzijom nisu u prvom redu konkretni pojedinci, već prije, veliki Drugi; možemo stoga reći da staljinizam ima vrijednost ontološkog dokaza za postojanje velikog Drugog" (Žižek 2002: 265). Stoga je unutar jednog konkretnog prostora njegov lik bio sveprotežan. Izmaknut od većine društvenih, političkih i ekonomskih nedaća - vrhovni autoritet božanskih moći ${ }^{5}$. Pa ipak, više je riječ o slici negoli konkretnom pojedincu. Jure Kaštelan najbolje je izrekao protežnost njegova autoriteta - „Rasti i cvjetaj pod zvijezdom slobode, / pod Rukom Partije / i pod srcem Tita" (Pjesme o mojoj zemlji) - koji obuhvaća istovremeno i snagu i emociju i bez kojega ne bi ničega bilo, baš suprotno Humboldtovoj izreci ,najbolja je ona vladavina, koja se čini suvišnom". No, da se vladavina ne bi činila suvišnom, a da ju se smatra dobrom, trebalo je iluziju, koja je uvijek jednim dijelom u realnom, učiniti obuhvatnijom. Stoga mnoge pjesme, usmene osobito, koje govore o životu partizana, stradanjima i borbi ne bi bile prihvaćene da nisu odgovarale kolektivnim interesima. NOB-e je iznijela seljačka klasa, Jugoslavija je do početka rata bila pretežno ruralna zemlja. U jednoj od najpopularnijih partizanskih pjesama - Seljačkoj torbi - govori se o skromnosti torbe/naroda, ali i moći da održava na životu čitavu borbu protiv fašizma. Iluzija, prisvajanje zasluga zapravo je klasičan panoptikon, u hijerahiziranom društvu ne smiju biti vidljive hijerarhije, ali ih se mora osjećati. Iluzija je u sljedećim premisama: seljačka torba hrani/spašava narod u borbi, na čelu borbe pro-

\footnotetext{
${ }^{5}$ Ovisno o perspektivi, Titova se slika u vlasti različito definirala kao totalitarna, autoritarna pa i s elementima liberalne vladavine.
} 
tiv fašizma je Tito te sud o tim premisama, odnosno zaključku - Tito ima funkciju torbe, hrani/spašava narod u borbi. Riječ je o prihvaćanju induktivnog slijeda zaključivanja, od nižeg reda k višem, pa i utoliko što se kolektivitet naroda dovodi do podređenosti pojedinačnome, realnom, a potom i slici realnoga. Drugim riječima, uspješnost imaginarne slike, već je rečeno, ovisi o njezinoj uvjerljivosti. Zasigurno će biti to uvjerljivija što je trajnija, odnosno što je udio tradicije u njoj veći. Maja Bošković Stulli ustvrdila je kako partizanske pjesme često nisu nastajale ex nihilo, nego su se sadržajem ili melodijski, odnosno motivski prilagođavale već postojećim pjesmama ${ }^{6}$. Štoviše, čak su i neke pjesme iz žanrovskoga kruga Muka isusovih bliske partizanskim pjesmama (Bošković-Stulli 1971: 341342). U značenju riječi tradicija, koja znači predaju, ključna je ideja dodira, kulturoloških, tijekom vremena. Budući da je ona poruka (Bart 1979: 230) koja se očituje, dijelom i u jeziku, onda se već približila ne samo mitu već i slici s obzirom da se uvijek na neki način prikazuje. O čemu je riječ? Valja nam pobliže objasniti te veze. Ako se mit obnavlja prisilom na ponavljanje (Freud 1986) i transkodiranjem (Lévi-Strauss 2011) onda on korespondira sa statusom slike onih objekata koje interaktivno ponavljaju dvostrukost - vlastitost, sebe kao objekt, te objekt prikaza. Komunikacija s njima jest transkodiranje vidljivog prema osjetilnom i spoznajnom. S obzirom da se ,vizualni simbolizam, primarni oblik simbolizma u kulturi razdvojio od svoje ikonografske ili metaforičke uloge te se rutinski počeo smatrati poklapanjem sa stvarnošću" (Jenks 2002: 29-30) slika je modelski preuzela funkcije i sadržaje svakodnevice. Jednom je zamijenivši, ne prilagođavajući se više diktatu vanjskog faktora, već vlastitim strukturama, ona generira neprekidnu semiozu bez referenata koja poprima karakter mita. Drugim riječima, sliku tradicije čije obrise određuje pogled sadašnjosti, opisuje i stvara, zapravo, mit (Sorel 2007: 359-367).

Naravno da su mediji sa svojim propagandno-spektakličnim učincima pridonijeli kultivizaciji, odnosno proizvodnja mita bila je način kontrole. Iza svih Titovih emanacija stoji pojam autoriteta. No, taj je autoritet klasnoga karaktera. Autoritet je dobiven, točnije zarađen zaslugama tijekom NOB-a i na temelju tog simboličkog kapitala uspostavljena je i ne samo simbolička već i stvarna moć. Nije se dogodilo ništa drugo negoli

\footnotetext{
${ }^{6}$ Često dolazi samo do promjena imena aktera pjesama, tako da su u partizanskim varijantama oni najčešće Tito, partizani, borci i sl. (cf. Bošković-Stulli 1971: 334-335).
} 
potvrdilo faktično stanje - put u besklasno društvo ostao je samo put. No, tom putu pridonijela je i pjesma: „Živi narod i narodno pravo / i drug Tito koji nam ga davo” ili: „Druže Tito, oče domovine, / Primi pozdrav naše omladine" (Rihtman-Auguštin, Bezić 1977). Performativna uloga pjesništva, i to uspješnoga, kakva se posvuda nalazi, najpoznatija možda u pjesmi Lili Marlen koju je prva izvodila Lale Andersen, kasnije i Marlene Dietrich?

Ne treba smetnuti s uma kako su, u skopičkoj kulturi koja se ubrzano nakon rata razvijala, pogled, odnosno slika povezani s nadzorom.

Od 1945. godine nova vlast u potpunosti menja čitavu ikonosferu i, osim konkretnim političkim zahvatima, deluje i na promeni simboličkog, vizuelnog plana, stvarajući jedan sasvim novi znakovni sistem koji je trebalo da bude, a u jednom kraćem periodu i jeste bio, metafora apsolutne vlasti - Partije i, pre svega, jednog čoveka na njenom čelu - Josipa Broza Tita. Ovo se najbolje očitavalo u brisanju gotovo svih označitelja prethodnog režima, državnog, ekonomskog i društvenog uređenja i kulturnog modela perioda do 1941. godine (Jakac 2009: 129).

Pjesništvu je sredstvo djelovanja metafora, putem nje imaginarno i slikovito zadobiva status realnog. Paradoks? Ne, metafora svojom performativnošću sukreira zbilju, poznato nam je iz kognitivne lingvistike. Ukoliko je u zbilji nešto opisivo prividom onda ga i metafora sukreira. Zapravo bi se moglo reći kako je Tito slika lule, ne i lula, da parafraziram glasovitu sliku Renea Magritea. Ranko Igrić je posve svjestan te skopičke varke, naglašenoga privida. U satiričko-ironijskoj pjesmi Portret maršala Tita prva dva stiha - „,̌ovjek koji ne zna za pozu / teško pristaje na poziranje" te posljednja dva ,tito opravdano zamišljen ostaje / portret odlazi svojim poslom" - apostrofiraju tu razdvojenost objekta i njegove predodžbe, stvarnosti i njezine slike. Štoviše, portret, slika odlazi „svojim poslom", oni su performativni. I u trenutku njegove smrti, zapravo tek tada ime postaje znak koji se desetljećima konstruirao. Stoga niti ironija nema snagu ironije, već suprotno - potvrde objekta. Više nije riječ o odgodi prisustva nego o odsustvu realnog. Tito zapravo nije niti postojao. Ukoliko je ime znak onda njegov pseudonim govori o odsutnoj prisutnosti samog imena. Kako psihoanaliza kaže odsutno ime Oca djelotvornije je od prisutnoga, jer djeluje snagom imena koje samo je autoritet. Na tim općim mje-

\footnotetext{
${ }^{7}$ Kurioziteta radi, pjesma je prvi put izvedena 18. kolovoza 1941. na Radio Beogradu.
} 
stima teorije konstituira se, sasvim spontano, treba biti iskren, i pjesništvo sa svojim općim mjestima nekroloških govora. Očit je primjer pjesma Giacoma Scottija Na vijest o Titovoj smrti: „Ali ostavio si nam oružje: svoje ime. / I ostavio si nam zalog: svoje ime. / Ostavio si nam ponos: svoje ime. / I budućnost si nam ostavio, Tito, / u imenu svom" (Pešić 1981). Ime Tita označava, predstavlja njegovu ideju: nesvrstanost, jednakost među narodima (bratstvo i jedinstvo) i samoupravljanje. Sudeći po pjesmi, Ime je Sve, ono je aksiom - Bog, izvan kojega nema ničega doli ništavila. Eshatološka misao u biti povijesti vidi slobodu, a prva je dimenzija vremena budućnost (Taubes 2009: 11-13).

Slika Tita bila je društvena činjenica, bilo da je riječ o pontyjevskim „tjelesnim pogledima” (Merleau-Ponty 1984) ili pak njoj kao ideološkom panoptikumu. Dva pitanja treba postaviti i pokušati odgovoriti na njih: što se vidjelo u pjesničkim slikama o prvom sinu domovine i kako su se one prezentirale.

U poznatoj pjesmi Vladimira Nazora Titov naprijed prikazan je hrabrim i odlučnim ${ }^{8}$, kao i u Pjesmama o mojoj zemlji Jure Kaštelana gdje je Tito suprotstavljen silama tame prikazan kao spasitelj, borac protiv nepravde, zaštitnik slabih i nemoćnih, on je onaj koji ulijeva nadu, koji donosi slavu i mir. Ili, puno kasnije, kada Anka Žagar u pjesmi Tito apostrofira bratstvo i jedinstvo ${ }^{9}$, krilatica koja označava jedan od najdojmljivijih ideoloških zakona Jugoslavije.

Svim je pjesmama zajednička apoteoza. Ona ne samo da znači uzdizanje među bogove, kao u Grčkoj, nego, kasnije u Rimu - imperatori su se također uzdizali među njih. S jedne strane one su pohvale vrijednostima, koje često, zapravo, i nisu njegove, ali kako je Tito metonimija antifašističke borbe i, kasnije, Partije/vlasti tako su i pohvale njemu pripisivane $^{10}$. Ne treba smetnuti s uma da je puno pjesama, osobito nakon rata, bilo posve prigodnih, pretjerivanja u svakom pogledu u kojima patetika

8 „Okreni se i vrati u nizine, / Da kosti griješ kod ognjišta svoga, / Pokoran i tih; najveći je zakon / Čovječiji: živjet, ma i kako bilo! // To avet reče; on očima bljesne / I vatru prospe iz plamenih zjenica; / Ošinu konja i neman pregazi, / Pa viknu s visa: / «Naprijed»" (Nazor 1946).

9 „A biljana biljana platno rezala / od Triglava do Ohrida” (Pešić 1981).

${ }^{10}$ Interesantno je primijetiti kako mu se pripisuju samo pozitivne osobine Partije, dok one negativne ostaju Partiji samoj. 
i manirizacija bivaju rezultat udvorništva. U tom smislu riječ je o didaktičkoj književnosti s jasnim ideološkim porukama ${ }^{11}$. Stari je to stav kojega je još u Pismima o estetskom odgoju čovjeka zastupao Friedrich Schiller (Schiller 2006), implicirajući kako je estetski ujedno i etički i politički odgoj. Ukoliko su prihvaćene estetske vrijednosti Tita - ljepota, dobrota, ispravnost itd., utoliko se one dijelom instrumentaliziraju.

Naravno, naš bi narod rekao - ,za dobrim se konjem prašina diže”, tako se u hrvatskome prostoru o Josipu Brozu najčešće govori pro et contra. Tragični događaji s početka devedesetih godina također govore o tome, ovisi čiji je pogled, jednima je svjetski državnik, drugima - totalitarist. Mislim da je pjesma, usprkos svima, rekla što o tome misli.

\section{Literatura}

Assmann J., 2005, Kulturno pamćenje, prev. V. Preljević, Zenica.

Bart R., 1979, Književnost, mitologija, semiologija, prev. I. Čolović, Beograd.

Biti M., Marot-Kiš D., 2008, Poetika uma, Zagreb.

Biti V., 2000, Strano tijelo pri/povijesti, Zagreb.

Bošković-Stulli M., 1971, Narodna poezija naše oslobodilačke borbe kao problem suvremenog folklornog stvaralaštva, u: M. Bošković-Stulli, Usmena književnost, Zagreb, s. 317-355.

Cipra M., 2003, Temelji onotologije, Zagreb.

Connerton P., 2004, Kako se društva sjećaju, prev. Z. Židovec, Zagreb.

Čulinović-Konstatinović V., 1989, Aždajkinja iz Manite Drage, Split.

Freud S., 1986, S onu stranu načela ugode, u: Budućnost jedne iluzije, prev. B. Buden, Zagreb.

Jakac B., 2009, Portret Maršala Tita, u Kultura sjećanja 1945. Povijesni lomovi i svladavanje prošlosti, Zagreb.

Janićijević J., 1986, U znaku Moloha, antropološki ogled o žrtvovanju, Beograd.

Jenks Ch., 2002, Središnja uloga oka u zapadnoj kulturi, prev. Z. Pavlić, u: Vizualna kultura, Zagreb.

Kolsto P., 2005, Myths and Boundaries in Southeast Europe, London.

11 „Taj čovjek na vrhu svjeta / obraća se ljudima / i priča im svakojake pojedinosti, / o ljudskoj sreći, o ljepoti, i praštanju. / Mi dijelimo njegove osjećaje, / sudbinu, njegove poglede i volju / I kroz zemlje u kojima straže bdiju / putevi vode slobodi" - Bilješke za рjesти о Вrozu (Pešić 1981). 
Lévi-Strauss C., 1978, Divlja misao, prev. J. i B. Jelić, Beograd.

Lévi-Strauss C., 2011, Mitologike, goli čovek, prev. A. Horvat, P. Sekeruš, V. Manić, I. Utornik, Novi Sad.

Löwith K., 1990, Svjetska povijest i događanje spasa, prev. M. Vukić, Zagreb.

Merleau-Ponty M., 1984, Struktura ponašanja, prev. B. Gojković, Beograd.

Nazor V., 1946, Legenda o Drugu Titu, Zagreb.

Pešić M.S., 1981, Kad te zaboli duša: Jugoslovenska poezija o Titu, Beograd.

Propp V.J., 1982, Morfologija bajke, prev. P. Vujičić, R. Matijašević, M. Vuković, Beograd.

Rihtman-Auguštin D., 1975, Kultura i umjetnost u NOB-u i socijalističkoj revoluciji u Hrvatskoj, Institut za historiju radničkog pokreta/August Cesarec Zagreb.

Rihtman-Auguštin D., Bezić J., 1977, Partizanski folklor o Titu, „Narodna umjetnost” br. 1, vol. 14.

Schiller F., 2006, Pismima o estetskom odgoju čovjeka, prev. D. Torjanac, Zagreb.

Slamnig I., 1965, Pjesma kao faktor kolektivne svijest, u: I. Slamnig, Disciplina mašte, Zagreb.

Sorel S., 2007, Tradicija i mediteranizam u poeziji, „Croatica et Slavica Iadertina” br. 3, Zadar.

Taubes J., 2009, Zapadna eshatologija, prev. D. Davidović, Zagreb.

Zečević D., 1975, Pučke književne tvorevine između umjetnosti i revolucije, u: NOB kultura i umjetnost u Hrvatskoj, Zagreb.

Žižek S., 2002, Sublimni objekt ideologije, prev. N. Jovanović, D. Kršić, I. Molek, Zagreb. 